\title{
Antirollover Experimental Method for a Liquid Tank Semitrailer
}

\author{
Miao Yu, ${ }^{1}$ Shiwu Li, ${ }^{1}$ Wencai Sun $\mathbb{D}^{1},{ }^{1}$ Xue Wen $\mathbb{D}^{1},{ }^{1}$ and Dongye $\mathrm{Lv}^{2}$ \\ ${ }^{1}$ School of Jilin University, Transportation College, Changchun 130000, China \\ ${ }^{2}$ Department of Transportation of Jilin Province, Changchun 130000, China \\ Correspondence should be addressed to Wencai Sun; swcai@163.com
}

Received 19 March 2020; Revised 12 July 2020; Accepted 27 August 2020; Published 15 September 2020

Academic Editor: Jose E. Naranjo

Copyright $\odot 2020$ Miao Yu et al. This is an open access article distributed under the Creative Commons Attribution License, which permits unrestricted use, distribution, and reproduction in any medium, provided the original work is properly cited.

\begin{abstract}
The liquid tank semitrailer has higher centroid and poor stability, and the vehicle is prone to rollover when turning or changing lanes at high speed. Thus, many companies have developed active antirollover systems in recent years. But the systems' antirollover capabilities are different. However, there are no specific test conditions and test standards for antirollover systems. Taking this as a starting point, first, an automotive intelligent security cloud terminal and a multiaxis sensor are selected for the test data acquisition, and a remote data acquisition system based on a mobile signal is established. Second, a vehicle road test scheme with a free choice of route is designed. Set the rollover trigger conditions, obtain the test data through the database, and classify the data into dangerous scenarios. Third, the typical scenarios with rollover risk are obtained by data fitting. Finally, the typical antirollover system test conditions of the liquid tank semitrailer are obtained by optimizing and analysing the typical scenarios through the simulation software. The results show that the J-steering test with a turning radius of $45 \mathrm{~m}$ in both clockwise and counterclockwise directions can be used as an accurate typical test condition of the antirollover system of liquid tank semitrailers.
\end{abstract}

\section{Introduction}

Liquid goods are mostly transported by liquid tank semitrailers; thus, the centroid of gravity of the body will be very high $[1,2]$. Moreover, a liquid is prone to shaking during such movement [3]. Hence, the stability of liquid tank trucks is much worse than that of passenger cars, which results in the incidence of traffic accidents increasing each year. Once a liquid tank semitrailer has a traffic accident, according to the particularity of the liquid, the accident can pose a great safety hazard to the driver and also cause great damage to the surrounding environment. In response to this situation, many antirollover technologies have emerged in recent years. The active rollover prevention (ARP) systems, which are powered by the advancement of onboard sensing and actuating technology, such as active steering control, active suspension, differential braking, and active antirollover preventer [4-9]. Passive warning-based systems are also emerged [10]. Within a PWS, the rollover propensity is detected or predicted throughout a rollover index, and then, a warning is provided to alert the driver to command corrective action.

However, a method to test and evaluate the ability to prevent rollover and standardize the rollover test standard for liquid tank semitrailers has not been reported. In fact, such a method has very important theoretical value and practical significance for research on the driving conditions of liquid tank semitrailers. Thus, this paper takes this point as an entry point for the study.

First, an automotive intelligent security cloud terminal and a multiaxis sensor are selected for the test data acquisition equipment. Then, a vehicle road test scheme with a free choice of route is designed in this paper. A remote data acquisition system based on a mobile signal has risk of rollover. Finally, the characteristic fragments of typical data of a liquid tank semitrailer in a dangerous state are obtained through a summary and verification. The obtained conclusions will provide data support and a basis for the subsequent formulation of the antirollover test conditions for semitrailer transport vehicles. 


\section{Data Collection}

2.1. Design of the Test Scheme. In this part, a vehicle road test scheme with a free choice of route is designed to collect driving data. The driving routes and driving time are not specific requirements and only follow the driver's need to complete the driving process. The acquisition time of the test data is not limited. The experimental data collection equipment is installed on the test vehicle, and real-time data are collected and transmitted remotely and then stored. The operating principle of the experimental data acquisition system is shown in Figure 1.

The rollover threshold refers to the lateral acceleration that the vehicle is subjected to when it starts to roll over. A large rollover threshold indicates high side-turn stability performance of the vehicle. The vehicle roll angle is a variable quantity that reflects the body roll state. When the vehicle roll angle keeps increasing and exceeds the rollover threshold, it will cause the vehicle to roll over. Therefore, the parameters considered in this paper are the vehicle roll angle and lateral acceleration.

2.2. Acquisition Equipment Installation. In this paper, the acquisition of vehicle driving data is based on the remote data acquisition of a mobile signal. The transmission signal of this system is not easily influenced by environmental factors. Additionally, the resulting measurement data can be transmitted to the cloud in real time, making it convenient to view driving data in real time. Since the test needs to collect a large amount of data, including the vehicle's running status, angular velocity, acceleration, and angle of each direction, the collection equipment include the automotive intelligent safety cloud terminal "Nicigo" and a nine-axis sensor, as shown in Figure 2.

The equipment installation vehicle is Dongfeng Tianlong (model DFL4251AX16A). As the installation semitrailer is a dangerous goods liquid tanker and the rollover tendency tends to be for the rear trailer, a nine-axis gyroscope is installed near the centroid of the trailer (the central of the second vertical beam cross section of the trailer frame, measured to be $5.7 \mathrm{~m}$ away from the rear of the vehicle). The installation location is shown in Figure 3, and the overall installation position is shown in Figure 4.

\section{Data Collection of the Driving Conditions}

To intuitively identify the dangerous scenario categories and effectively analyse the causes of rollover accidents, a database of the dangerous segments of the liquid tank semitrailers was established. The database was based on data transmitted to the cloud in real time.

3.1. Dangerous Scenario Classification. Before establishing a dangerous fragment database for dangerous goods transport vehicles, the dangerous scenarios were divided into the following scenarios: an abrupt deceleration, a sharp turn, a lane departure, and a collision warning.

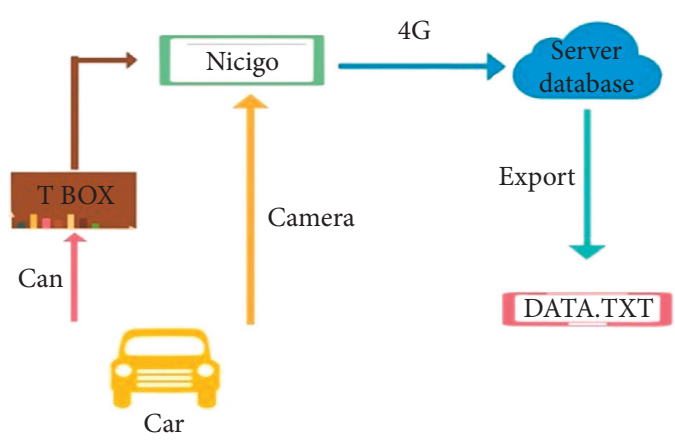

FIGURE 1: Operating principle of the experimental data acquisition system.

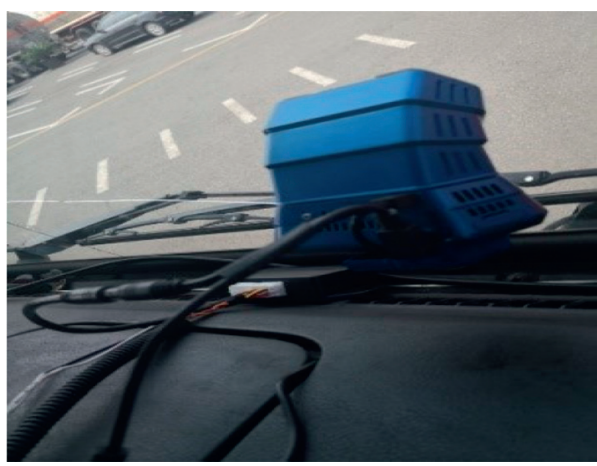

Figure 2: Automotive intelligent safety cloud terminal "Nicigo."

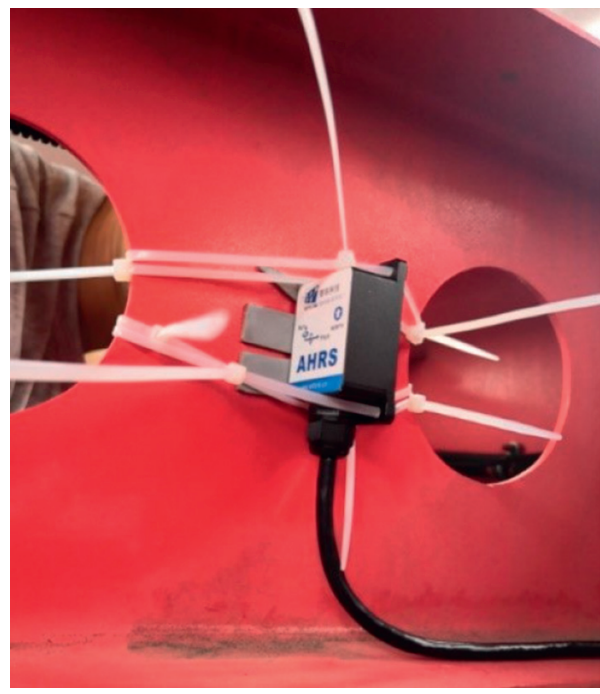

Figure 3: Nine-axis gyroscope installation.

For the rapid deceleration and collision warning scenarios, the vehicle braking distance and brake deceleration were set at a threshold according to the safe operating technical conditions of China's vehicle standard GB72582017.

For the sharp turn and lane departure scenarios, the vehicle mainly exhibits excessive lateral acceleration. According to the rollover threshold table for different types of vehicles, the lateral acceleration threshold of liquid tank 


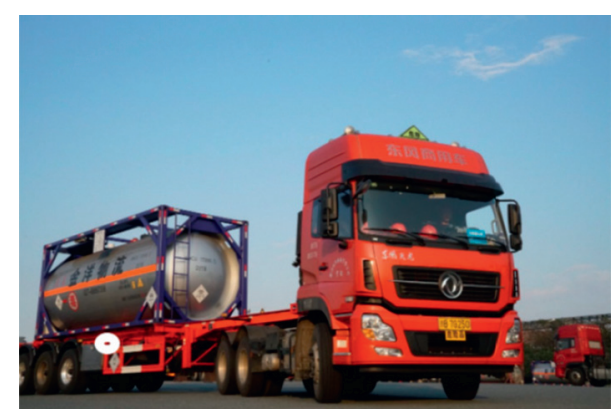

FIgURE 4: Nine-axis gyroscope installation position.

semitrailers is $0.4 \mathrm{~g}-0.6 \mathrm{~g}$. Because the test is a vehicle road test and not a rollover test on a proving ground, the threshold cannot be reached based on the actual vehicle operation. Therefore, the trigger condition for the rollover scenario was set to $V \geq 30 \mathrm{~km} / \mathrm{h}$. The absolute value of the lateral acceleration $a_{y}$ was set to $0.2 \mathrm{~g}$ or more.

\subsection{Establishment of a Database for the Driving Conditions.}

We establish a liquid tank semitrailer driving database that includes three parts: event statistics, data display, and system management. The database stores data collected by the automotive intelligent safety cloud terminal "Nicigo" and the nine-axis sensor. The data mainly include basic information such as the license plate, trip ID, device number, start time, end time, duration, and distance and dangerous scenario information such as rapid turns, abrupt decelerations, lane departures, and collision warnings.

We set up a data query and presentation page to provide basic information about the vehicle, a GPS trajectory display, images or videos of hazardous scenario alerts, and statistics of early warning events.

As shown in Table 1, based on the data uploaded by the intelligent terminal, the system can determine the start time and distance of each segment of the trip and a number of abnormal conditions such as sharp turns, abrupt decelerations, lane departures, and collision warnings.

In this way, the frequency of various working conditions can be directly obtained, and the working condition categories that need to be researched and calibrated are determined.

A total of 837,837 sets of data were collected in the database. The number and proportion of each early warning event were counted. The results are shown in Figure 5.

\section{Extraction of Dangerous Scenarios and the Design of Typical Test Conditions}

According to the statistics, sharp turns and lane departure warnings directly affect the rollover of liquid tank semitrailers. Hence, we analyse the rollover test conditions of liquid tank semitrailers under the above two conditions.

4.1. Dangerous Scenario Extraction. The sharp turns and lane departure warning events were organized according to the driving speed at the time of the event. To obtain an accurate speed segment, the lane departure warning events were divided into accelerated lane changing scenarios, uniform motion lane changing scenarios, and braking lane changing scenarios.

The accelerated lane changing scenarios involved vehicle lane changing behaviour during acceleration. Because the vehicle speed changes during actual operation, the scenarios where the vehicle speed range increases by more than $3 \mathrm{~km} / \mathrm{h}$ before and after the trigger point are defined as acceleration lane changing scenarios, the scenarios where the vehicle speed range changes by less than $3 \mathrm{~km} / \mathrm{h}$ are defined as uniform motion lane changing scenarios, and the scenarios where the vehicle speed range decreases by more than $3 \mathrm{~km} / \mathrm{h}$ are considered to be braking lane changing scenarios.

A histogram of the driving speed ratios under different test conditions was produced as shown in Figure 6.

Due to the volatility of the data, wavelet noise filtering with dimensionality reduction was employed to process the noise of data. In addition, driving segments that exhibit sharp turns, accelerated lane changing scenarios, braking lane changing scenarios, and uniform lane changing scenarios were selected. Then, the correlation between the selected feature fragments and the overall feature fragments in which they were classified was calculated. The feature fragments with a correlation coefficient greater than 0.8 (strongly related) were selected.

It can be seen from the speed map (Figure 6) that the vehicle speed was generally less than $50 \mathrm{~km} / \mathrm{h}$ and greater than $35 \mathrm{~km} / \mathrm{h}$ when making a turn onto the ramp. Therefore, the change in the vehicle's lateral acceleration roll angle was compared with the initial speed of $35 \mathrm{~km} / \mathrm{h}$ and the speed change of $5 \mathrm{~km} / \mathrm{h}$.

The change in the lateral acceleration in the sharp turn scenarios is shown in Figure 7, and the change in the roll angle is shown in Figure 8.

According to Figures 7 and 8, it can be concluded that the greater the vehicle speed is when making a turn on a ramp, the greater the lateral acceleration and the roll angle; in this regime, liquid tank semitrailers are in a dangerous state.

In the accelerated lane changing scenarios, uniform lane changing scenarios, and braking lane changing scenarios, the maximum speed range was $45 \mathrm{~km} / \mathrm{h}-65 \mathrm{~km} / \mathrm{h}$. For the convenience of analysis, lane changing scenarios with initial speeds of $45 \mathrm{~km} / \mathrm{h}, 55 \mathrm{~km} / \mathrm{h}$, and $65 \mathrm{~km} / \mathrm{h}$ were selected, and their lateral acceleration and vehicle roll angle data were compared. The comparative results are presented in the following.

The comparative results of the lateral acceleration and the vehicle roll angle data for the accelerated lane changing scenarios are shown in Figures 9 and 10.

The comparative results of the lateral acceleration and the vehicle roll angle data for the uniform lane changing scenarios are shown in Figures 11 and 12.

The comparative results of the lateral acceleration and the vehicle roll angle data for the breaking lane changing scenarios are shown in Figures 13 and 14.

By analysing the four scenarios of sharp turns, accelerated lane changing, uniform lane changing, and 
TABLE 1: Driving condition data center.

\begin{tabular}{|c|c|c|c|c|c|c|c|c|c|}
\hline $\begin{array}{l}\text { License plate } \\
\text { number }\end{array}$ & Journey ID & Device number & $\begin{array}{l}\text { Journey } \\
\text { start time }\end{array}$ & $\begin{array}{l}\text { Journey } \\
\text { end time }\end{array}$ & $\begin{array}{l}\text { Journey } \\
\text { duration }\end{array}$ & $\begin{array}{l}\text { Journey } \\
\text { distance }\end{array}$ & $\begin{array}{l}\text { Sharp } \\
\text { turn }\end{array}$ & Deceleration & $\begin{array}{c}\text { Lane } \\
\text { departure } \\
\text { warning (left) } \\
\end{array}$ \\
\hline ZhejiangB7F829 & 1568022108 & 862465030063269 & $\begin{array}{c}2019 / 9 / 9 \\
17: 41: 30\end{array}$ & $\begin{array}{c}2019 / 9 / 9 \\
17: 42: 56\end{array}$ & 1.43 & 0.35 & 0 & 0 & 0 \\
\hline ZhejiangB7F718 & 1568018469 & 862465030069225 & $\begin{array}{l}2019 / 9 / 9 \\
16: 40: 55\end{array}$ & $\begin{array}{l}2019 / 9 / 9 \\
16: 42: 38\end{array}$ & 1.72 & 0.12 & 0 & 0 & 0 \\
\hline ZhejiangB79698 & 1568018246 & 862465030068573 & $\begin{array}{c}2019 / 9 / 9 \\
16: 37: 12\end{array}$ & $\begin{array}{l}2019 / 9 / 9 \\
16: 37: 58\end{array}$ & 0.77 & 0.11 & 0 & 15 & 0 \\
\hline ZhejiangB79698 & 1568017804 & 862465030068573 & $\begin{array}{c}2019 / 9 / 9 \\
16: 29: 58\end{array}$ & $\begin{array}{c}2019 / 9 / 9 \\
16: 33: 37\end{array}$ & 3.65 & 1.16 & 0 & 0 & 0 \\
\hline ZhejiangB0N312 & 1568017142 & 862465030070264 & $\begin{array}{c}2019 / 9 / 9 \\
16: 18: 48\end{array}$ & $\begin{array}{c}2019 / 9 / 9 \\
16: 52: 04\end{array}$ & 33.27 & 14.37 & 1 & 1 & 2 \\
\hline ZhejiangB7A590 & 1568015576 & 862465030051645 & $\begin{array}{l}2019 / 9 / 9 \\
15: 52: 54\end{array}$ & $\begin{array}{l}2019 / 9 / 9 \\
15: 56: 20\end{array}$ & 3.43 & 0.53 & 0 & 0 & 0 \\
\hline ZhejiangB7F830 & 1568014559 & 862465030031530 & $\begin{array}{l}2019 / 9 / 9 \\
15: 35: 47\end{array}$ & $\begin{array}{c}2019 / 9 / 9 \\
15: 39: 37\end{array}$ & 3.83 & 1.07 & 0 & 1 & 0 \\
\hline ZhejiangB7F718 & 1568014501 & 862465030069255 & $\begin{array}{l}2019 / 9 / 9 \\
15: 34: 47\end{array}$ & $\begin{array}{c}2019 / 9 / 9 \\
16: 00: 47\end{array}$ & 26 & 14.37 & 4 & 4 & 2 \\
\hline
\end{tabular}

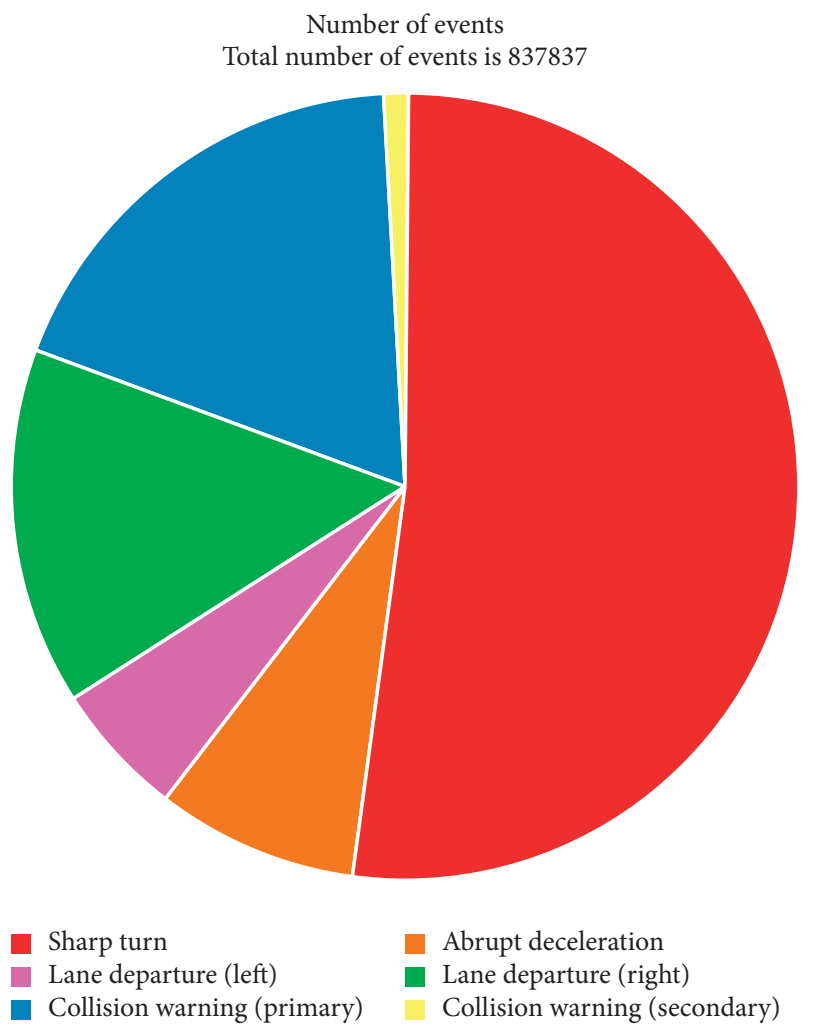

FIgURE 5: Statistics of number and proportion of early warning events.

decelerated lane changing, it can be concluded that the liquid tank semitrailer has the greatest lateral acceleration in the sharp turn scenarios. Additionally, the alarm speed is minimum when the lateral acceleration reaches the value in the sharp turn scenarios. In addition, the roll angle is the largest and is maintained for the longest time in the sharp turn scenarios. The liquid tank semitrailer has the greatest

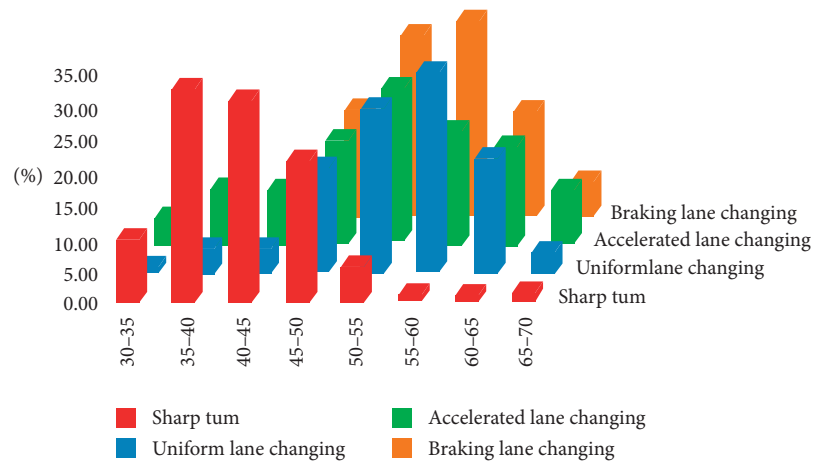

Figure 6: The histogram of driving speed ratios under different test conditions.

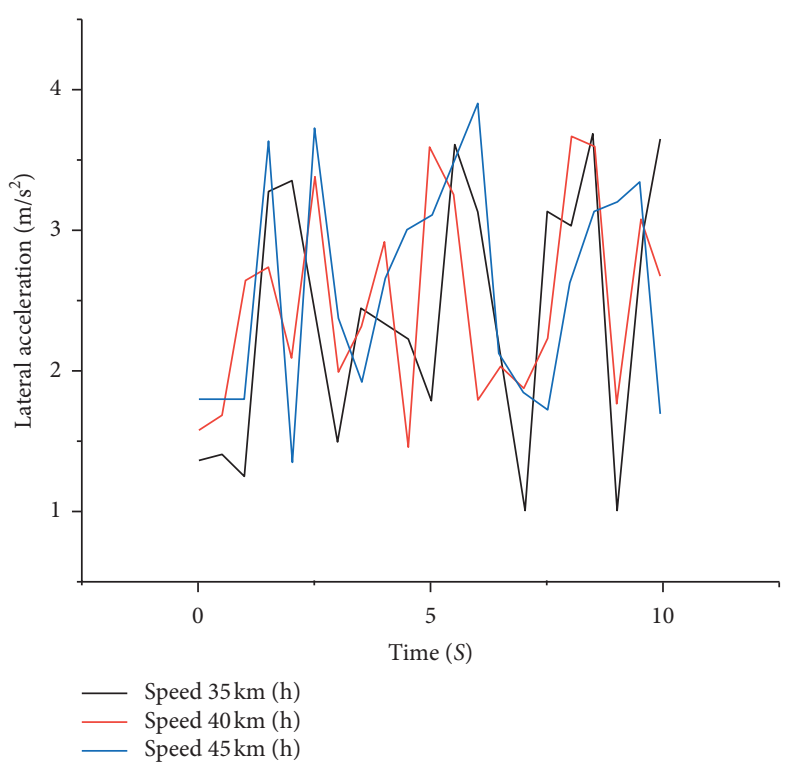

FIGURE 7: Lateral acceleration change of vehicle-turning scenarios. 


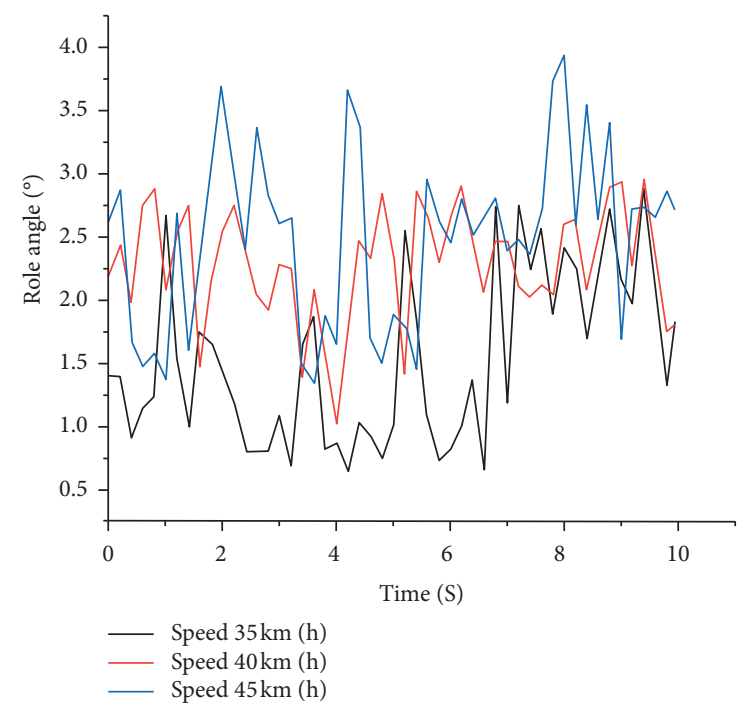

FIGURE 8: Roll angle change of vehicle-turning scenarios.

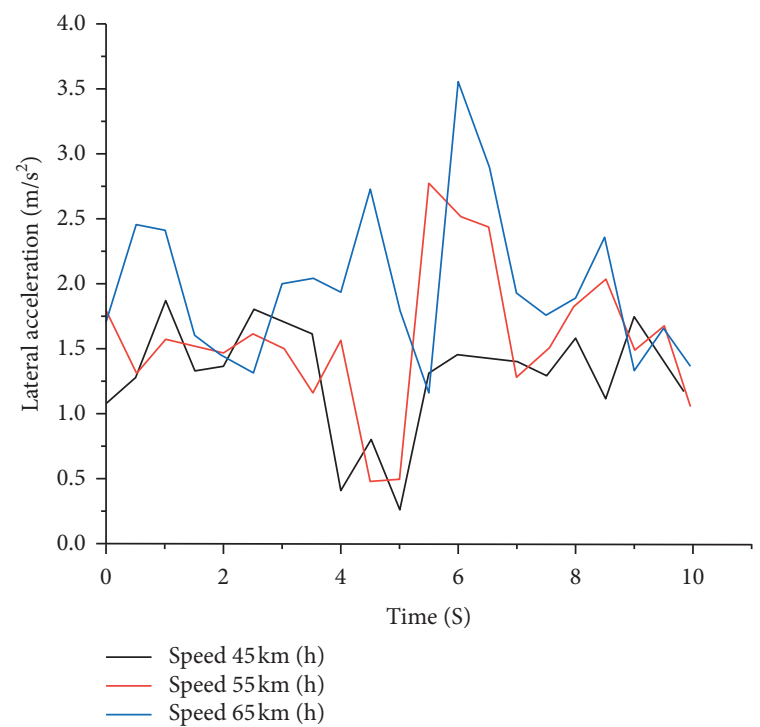

FIGURE 9: Lateral acceleration change of the accelerated lane changing scenarios.

tendency to roll over. Moreover, according to the early warning event of the liquid tank semitrailers in Figure 5, it can also be seen that the liquid tank semitrailers have the highest alarm probability in sharp turn scenarios. The alarm rate was more than $50 \%$ of the total rate for all rollover dangerous scenarios. In summary, the sharp turn scenarios were selected as the typical rollover test condition for liquid tank semitrailers.

4.2. Typical Test Condition Design. After confirming the sharp turn scenarios as the typical rollover test condition for liquid tank semitrailers, the initial speed and turn radius of the test need to be confirmed. If the turning radius is too small, it will increase the driving difficulty, and the speed threshold will be too low when the liquid tank semitrailer

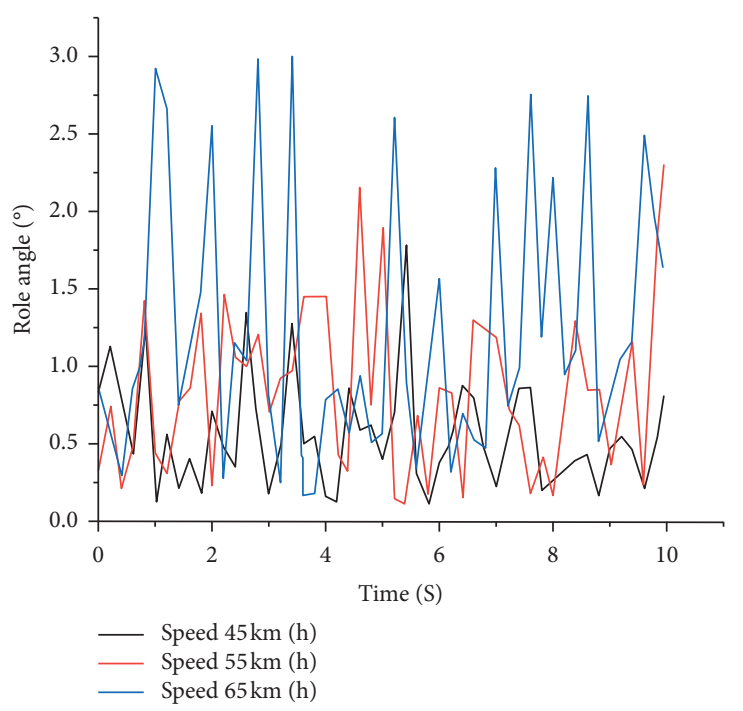

FIgURE 10: Roll angle change of the accelerated lane changing scenarios.

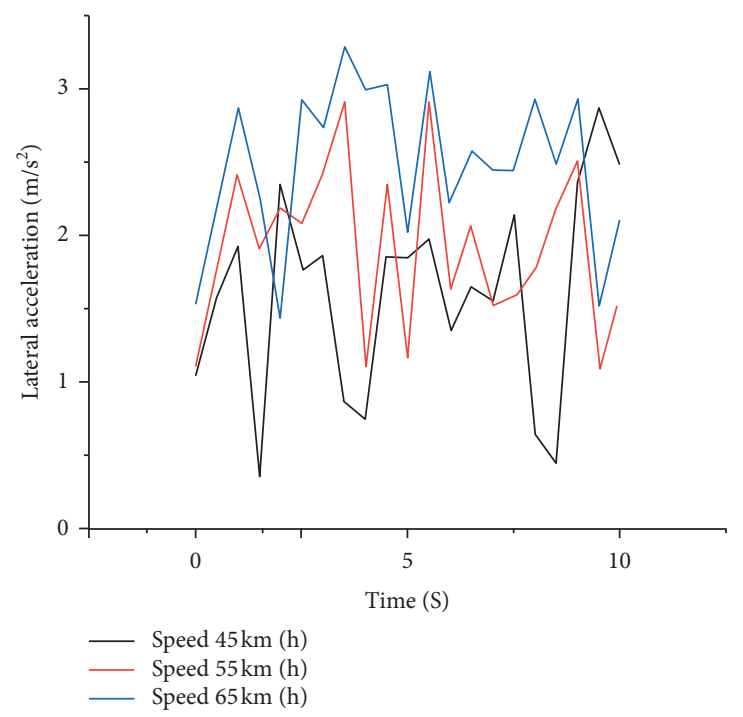

FIGURE 11: Lateral acceleration change of the uniform motion lane changing scenarios.

rolls over. Therefore, different curve radii were simulated using Trucksim 8.0. The road setting is shown in Figure 15. The minimum turning radius of the test liquid tank semitrailer is calculated to be $17 \mathrm{~m}$. However, the vehicle speed is too low when the specified radius ranges from 17 to $34 \mathrm{~m}$, and the simulation result is not obvious. Therefore, the minimum curve radius was set to $35 \mathrm{~m}$ and gradually increased by $5 \mathrm{~m}$. The rollover thresholds for each curve radius are shown in Table 2.

Table 2 shows that as the radius of the curve increases, the speed threshold required to reach the rollover state also increases. Since the typical test conditions are implemented in a professional test field, the turning radius during the test should not be too large. Because the maximum width of the test site is $80 \mathrm{~m}$, the turning radius should be less than $80 \mathrm{~m}$. 


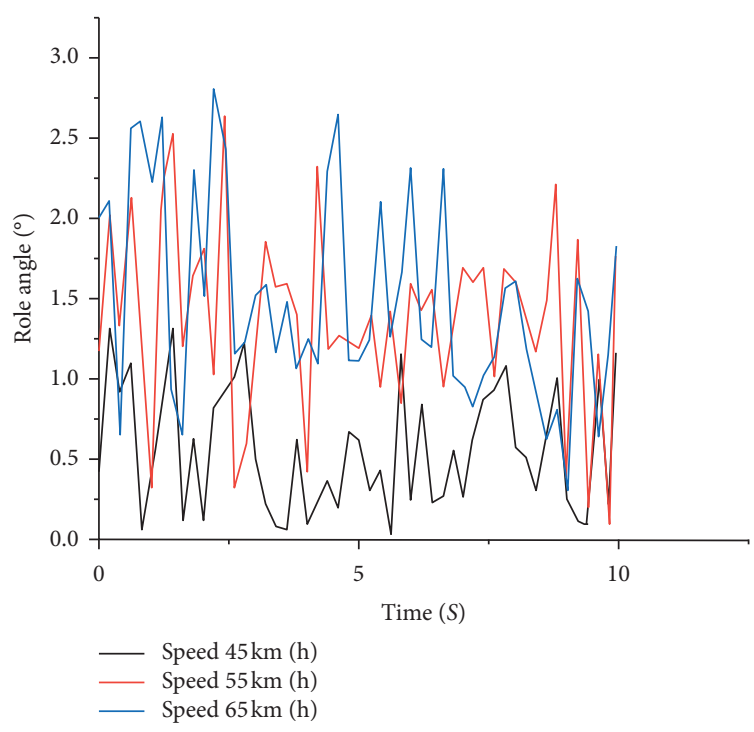

FIGURE 12: Roll angle change of the uniform motion lane changing scenarios.

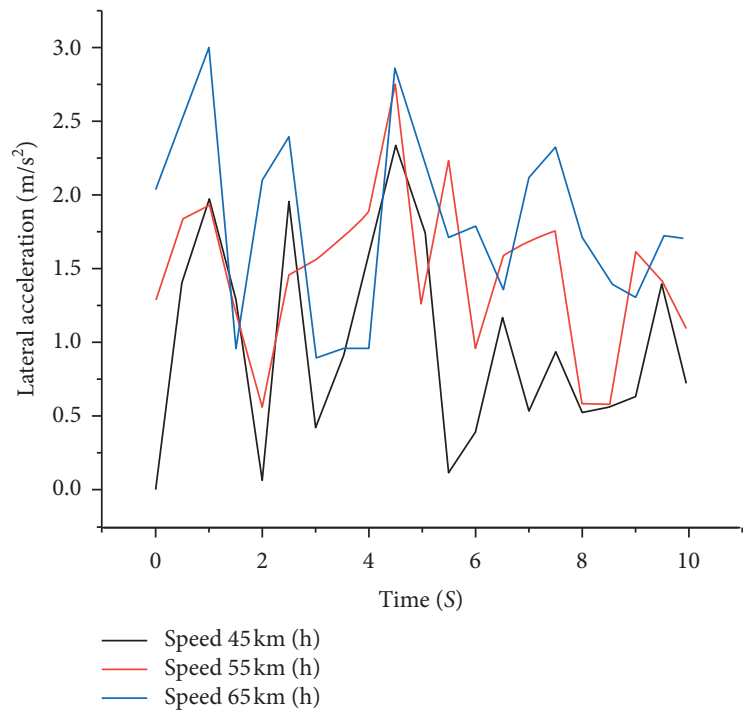

FIGURE 13: Lateral acceleration change of the braking lane changing scenarios.

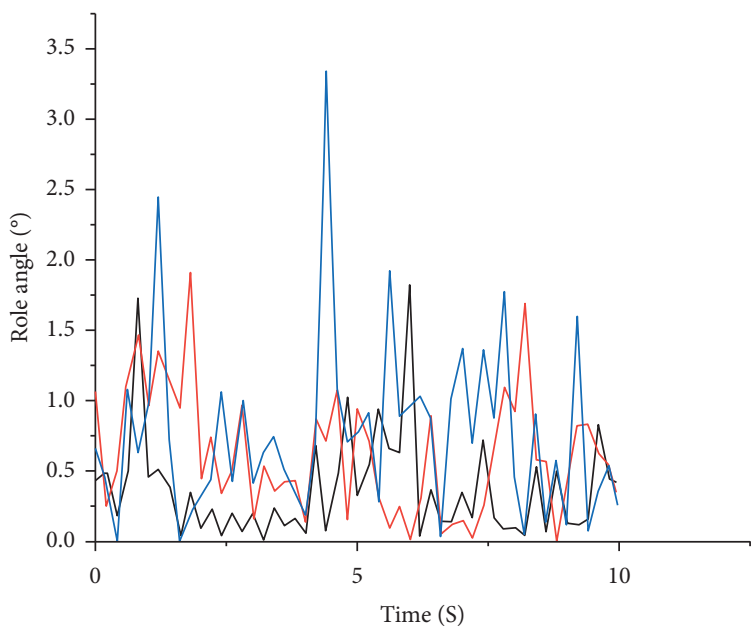

$$
\begin{aligned}
& \text { Speed } 45 \mathrm{~km}(\mathrm{~h}) \\
& \text { Speed } 55 \mathrm{~km}(\mathrm{~h}) \\
& \text { Speed } 65 \mathrm{~km}(\mathrm{~h})
\end{aligned}
$$

FIGURE 14: Roll angle change of the braking lane changing scenarios. 


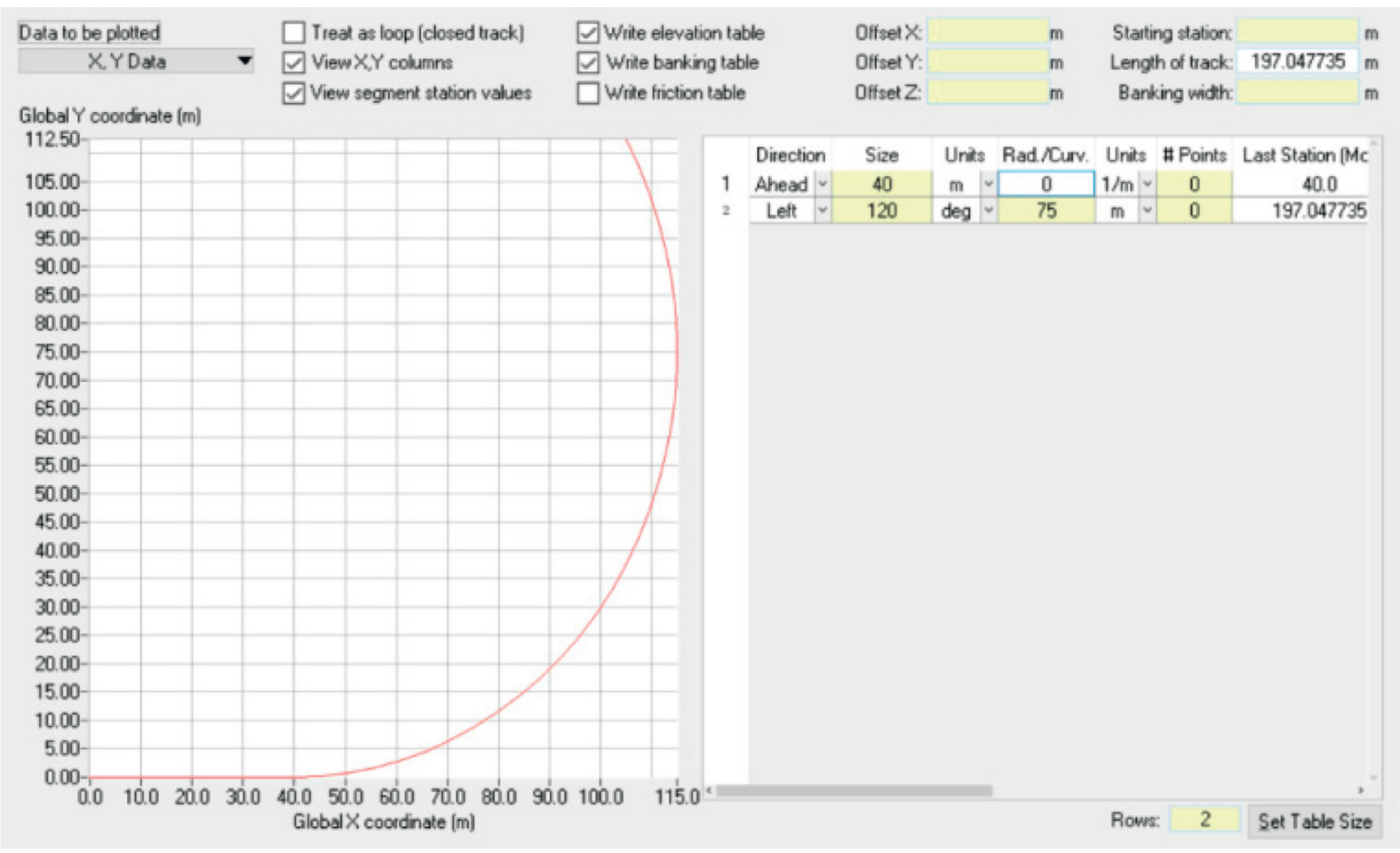

Figure 15: Road simulation settings.

TABLE 2: The rollover thresholds at each curve radius.

\begin{tabular}{lcc}
\hline $\begin{array}{l}\text { Curve } \\
\text { radius }(\mathrm{m})\end{array}$ & $\begin{array}{c}\text { Speed } \\
(\mathrm{km} / \mathrm{h})\end{array}$ & $\begin{array}{c}\text { Maximum } \\
\text { lateral acceleration }\left(\mathrm{m} / \mathrm{s}^{2}\right)\end{array}$ \\
\hline 35 & 39.7 & 3.98 \\
40 & 42.3 & 4.27 \\
45 & 44.5 & 4.02 \\
50 & 46.7 & 3.91 \\
55 & 48.8 & 3.81 \\
60 & 50.9 & 3.94 \\
65 & 52.8 & 3.75 \\
70 & 54.6 & 3.83 \\
75 & 56.4 & 3.76 \\
80 & 58.2 & 3.73 \\
85 & 59.9 & 3.83 \\
\hline
\end{tabular}

According to the simulation results and the actual operating conditions, it can be seen that after selecting the test route with a radius of $45 \mathrm{~m}$, the lateral acceleration is more obvious, and the vehicle speed is also within the range of the vehicle's usual speed conditions. Hence, the turning radius is determined to be $45 \mathrm{~m}$. Thus, the J-turn test in both clockwise and counterclockwise directions is employed. The test speed starts at $36 \mathrm{~km} / \mathrm{h}$ and gradually increases until the vehicle's roll cage touches the ground. The fastest safe speed at which the test vehicle completes the specified route of the required test site is obtained through repeated tests.

\section{Conclusions}

In this paper, a typical antirollover system test condition of the liquid tank semitrailer is obtained. An automotive intelligent security cloud terminal and a multiaxis sensor are selected for the test data acquisition, and a remote data acquisition system based on a mobile signal is established. A vehicle road test scheme with a free choice of route is designed. Set the rollover trigger conditions, obtain the test data through the database, and classify the data into dangerous scenarios. The typical scenarios with rollover risk are obtained by data fitting. The J-steering test with a turning radius of $45 \mathrm{~m}$ in both clockwise and counterclockwise directions is obtained as an accurate typical test condition of the antirollover system of liquid tank semitrailer. With this approach, the antirollover capability of different types of antirollover devices installed on the same vehicle model can be compared. Additionally, the limit of the speed of different type liquid tank semitrailers in test conditions can be obtained with the same method.

\section{Data Availability}

Basic data can be accessed by clicking the following link: http://60.12.8.195:9999/login.do.

\section{Conflicts of Interest}

The authors declare that there are no conflicts of interest regarding the publication of this paper.

\section{Acknowledgments}

This work was supported by the National Key Research and Development Program of China (Grant no. 2017YFC0804808), Jilin Province Science and Technology Development Plan 
Project (Grant no. 20180101074JC), and Jilin Provincial Department of Education "Thirteenth Five-Year" Science and Technology Research Project (Grant no. JJKH20190152KJ).

\section{References}

[1] National Highway Traffic Safety Administration's National Center for Statistics and Analysis, 2015 Motor Vehicle Crashes: Overview, U.S. Department of Transportation, Washington, DC, USA, 2016.

[2] B. Mohammed and W. Z. Jean, "Tractor-semitrailer model for vehicles carrying liquids," Vehicle System Dynamics, vol. 44, no. 11 , pp. 871-885, 2006

[3] S. Li, C. F. Zong, P. Xie, L. Y. Jiang, S. Qin, and L. M. Song, "Simulation study on the dynamic roll response of a partiallyfilled liquid tank vehicles," World Automation Congress (WAC), vol. 1, 2012.

[4] S. Yim, "Design of a preview controller for vehicle rollover prevention," IEEE Transactions on Vehicular Technology, vol. 60, no. 9, pp. 4271-4226, 2011.

[5] N. C. Parida, S. Raha, and A. Ramani, "Rollover-preventive force synthesis at active suspensions in a vehicle performing a severe maneuver with wheels lifted off," IEEE Transactions on Intelligent Transportation Systems, vol. 15, no. 6, pp. 25832594, Dec. 2014.

[6] B. Mashadi, M. Mokhtari-Alehashem, and H. Mostaghimi, "Active vehicle rollover control using a gyroscopic device," Proceedings of the Institution of Mechanical Engineers, Part D: Journal of Automobile Engineering, vol. 230, no. 14, pp. 1958-1971, 2016.

[7] A. Goodarzi, M. Naghibian, D. Choodan, and A. Khajepour, "Vehicle dynamics control by using a three-dimensional stabilizer pendulum system," Vehicle System Dynamics, vol. 54, no. 12, pp. 1671-1687, Aug. 2016.

[8] F. Wang and Y. Chen, "A novel active rollover preventer for ground vehicles based on continuous roll motion detection," ASME Transactions: Journal of Dynamic Systems, Measurement and Control, vol. 141, no. 1, 2019.

[9] F. Wang and Y. Chen, "Vehicle rollover prevention through a novel active rollover preventer," in Proceedings of the ASME Dynamic Systems and Control Conference Tysons Corner, VA, USA, October 2017.

[10] R. Rajamani, "Roll dynamics and rollover prevention," in Vehicle Dynamics and Control, pp. 427-456, Springer, New York, NY, USA, 2nd edition, 2012. 